\title{
Temperature-Dependent X-Ray Studies of Discotic Hexagonal Columnar Mesophases in Trinuclear Gold(I) Pyrazolate Complex
}

\begin{abstract}
Mohamad Azani Jalania, , , Hendrik O. Lintang ${ }^{b, c}$, Siew Ling Lee ${ }^{b, c}$, Juan Matmin ${ }^{b}$, Nur Fatiha Ghazallid, Leny Yuliati ${ }^{\mathrm{e}}$, Amy Zuria Abdul Ajidf, Mohd Izam Idrus

${ }^{a}$ Kolej GENIUS Insan, Universiti Sains Islam Malaysia, Kompleks PERMATA Insan, Bandar Baru Nilai, 71800 Nilai, Negeri Sembilan, Malaysia; ${ }^{\text {b }}$ Department of Chemistry, Faculty of Science, Universiti Teknologi Malaysia, 81310 UTM Johor Bahru, Johor, Malaysia; ' Centre of Sustainable Nanomaterials, Ibnu Sina Institute for Scientific and Industrial Research, Universiti Teknologi Malaysia, 81310 UTM Johor Bahru, Johor, Malaysia; ' School of Dental Sciences, Health Campus, Universiti Sains Malaysia, Kubang Kerian 16150, Kota Bharu, Kelantan; ${ }^{e} \mathrm{Ma}$ Chung Research Center for Photosynthetic Pigments (MRCPP), Universitas Ma Chung (UMC), Villa Puncak Tidar N-01, 65151, Malang, Jawa Timur, Indonesia; fUnit Pengurusan Makmal Universiti (UPMU) Blok T03 Bangunan UiRL, Universiti Teknologi Malaysia, 81310 UTM Johor Bahru, Johor, Malaysia
\end{abstract}

*For correspondence: mazani@usim.edu.my

Received: 28 Dec 2020

Accepted: 19 June 2021

(C) Copyright Jalani. This article is distributed under the terms of the Creative Commons Attribution License, which permits unrestricted use and redistribution provided that the original author and source are credited.

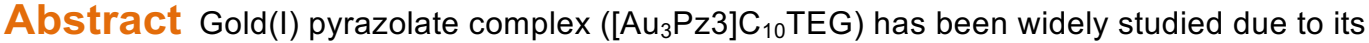
interesting liquid crystalline properties by exhibiting the discotic hexagonal columnar arrangement. Generally, the liquid crystalline properties of the gold complex were confirmed based on their differential scanning calorimetry thermogram and polarized optical microscopy (POM) images. However, there is still no in-depth study on the phase transition in liquid crystals of $\left[\mathrm{Au}_{3} \mathrm{Pz} 3\right] \mathrm{C}_{10} \mathrm{TEG}$ especially on its structural change at variable temperature. In this study, the resulting liquid crystalline properties of $\left[\mathrm{Au}_{3} \mathrm{Pz} 3\right] \mathrm{C}_{10} \mathrm{TEG}$ upon being heated and cooled was extensively demonstrated via variable-temperature POM (VT-POM) and small angle X-ray

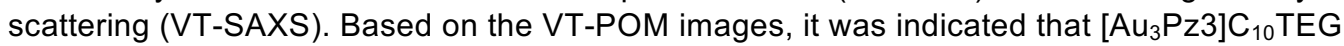
displayed a fan-shaped texture for typical arrangements of discotic hexagonal columnar of liquid crystals. Moreover, VT-SAXS results was in good agreement with the VT-POM images as it showed that $\left[\mathrm{Au}_{3} \mathrm{Pz} 3\right] \mathrm{C}_{10} \mathrm{TEG}$ might consist of two types of stacking system, which are ordered and disordered hexagonal discotic arrangements. Likewise, VT-SAXS analysis also demonstrated that hexagonal columnar mesophase of $\left[\mathrm{Au}_{3} \mathrm{Pz} 3\right] \mathrm{C}_{10} \mathrm{TEG}$ could be recovered even after the heating and cooling for two cycles.

Keywords: Gold(I) pyrazolate complex, Discotic, Hexagonal, Small angle X-ray scattering

\section{Introduction}

Liquid crystals (LCs) were defined as an intermediate region formed in between solid and liquids state of matters, having properties of both isotropic and crystalline phases [1]. The first example of LCs was 
studied by an Austrian botanist named Friedrich Reinitzer upon discovering an unusual melting pattern of cholesteryl benzoate compound [2]. Moreover, compounds that displayed liquid crystalline properties were also known as mesogens while its liquid crystalline phase can be referred as a mesophase [3]. Generally, LCs can be divided in two main groups that are thermotropic and lyotropic. The main difference between the two LCs groups is that thermotropic LCs does not involve any solvent and are highly dependent upon temperature changes. On the other hand, lyotropic LCs is displayed upon dissolved in a solvent at appropriate concentration to form a stage known as critical micelle concentration $[4,5]$. Moreover, based on the shape of the resulting mesogens, the thermotropic LCs can be further divided into two, which are calamitic and discotic LCs [6,7]. Calamitic LCs exhibit two kinds of mesophases, which are smectic (Smectic A and C) and nematic phases, while discotic LCs can give either nematic, columnar (nematic, hexagonal, rectangular and oblique) or lamellar phases as illustrated in Figure 1. Discotic LCs were commonly exhibited by molecules such as metal pyrazolate complexes, triphenylenes, and others upon having a flat and rigid aromatic center bearing several flexible chains. Later, this arrangement will form a long array of stacking between themselves to give a respective twodimensional (2D) arrangement that are important for effective charge-transfer [8-11].

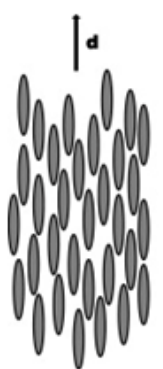

Nematic

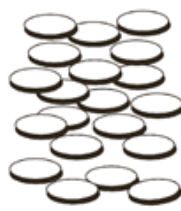

Discotic Nematic

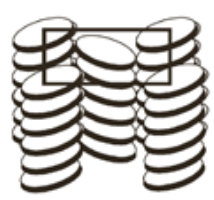

Rectangular a)

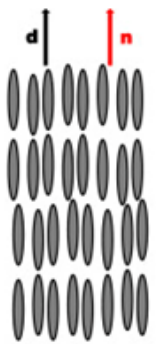

Smectic-A

d)

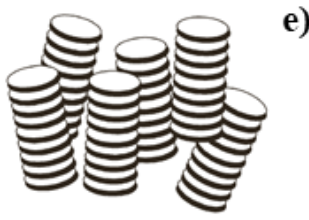

Nematic Columnar

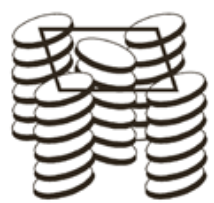

Oblique b)

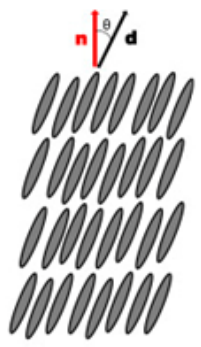

Smectic-C

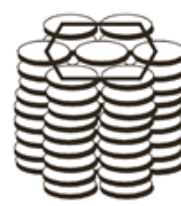

Hexagonal

h)

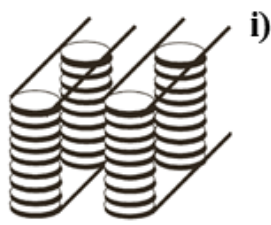

Lamellar

c)

Figure 1. The illustration of calamitic mesophases of a) nematic, b) Smectic A, c) Smectic C, and discotic arrangements of d) nematic, e) nematic columnar, f) hexagonal columnar, g) rectangular columnar, $h$ ) oblique columnar and i) lamellar columnar mesophases [6-7]

Noteworthy, recent studies showed that metal complexes were also capable to form a discotic columnar arrangement with additional liquid crystalline properties in their structures. For example, several research on trinuclear gold $(I)$ pyrazolate complexes reported that these metal complexes can behave as discotic mesogens with hexagonal columnar arrangements. Barbera et al. [12] have reported the first example of trinuclear gold complexes with interesting liquid crystalline properties by utilizing pyrazolate ligands that did not exhibit any mesogenic behavior in the first place. In the same year, Kim et al. [13] have successfully synthesized a series of trinuclear gold $(\mathrm{I})$ pyrazolate complexes bearing only three longchain alkyl-substituted pyrazoles, where two of the resulting gold complexes exhibited monotropic 
mesophases. In this case, gold complex with heptyl group attached to its 4 position in pyrazole ring gave mesogenic properties from 112 to $99{ }^{\circ} \mathrm{C}$ upon cooling, while the other gold complex with octyl group attached at the same position gave mesogenic properties from 85 to $61^{\circ} \mathrm{C}$. Other than that, more recent work by Lintang et al. [14] also reported the formation of discotic columnar LCs by gold(I) pyrazolate complex having amphiphilic decoxy triethylene glycol $\left(\left[\mathrm{Au}_{3} \mathrm{Pz}_{3}\right] \mathrm{C}_{10} \mathrm{TEG}\right)$ side arms. The gold complex exhibited a liquid crystalline behavior over a wide room temperature range between -3 to $44^{\circ} \mathrm{C}$ with fanshaped texture after aged for 12 hours. However, all the reported works only briefly mentioned the liquid crystalline behavior of their gold complexes with no in-depth study especially on their structural changes upon variable-temperature. The detailed structure of metal complexes in all reported works were summarized in Figure 2 as follows.

a)

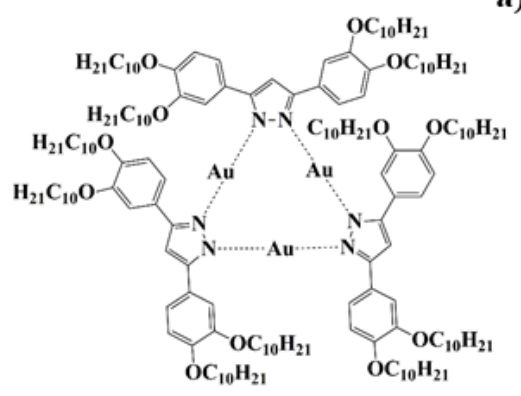

c)

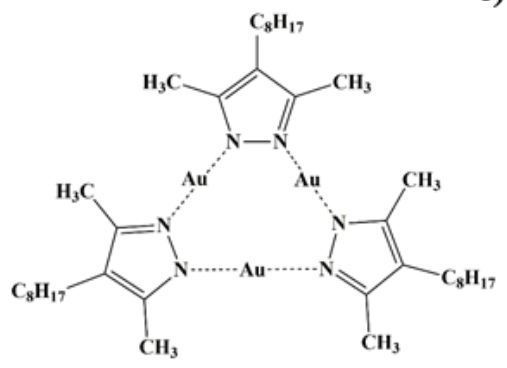

b)

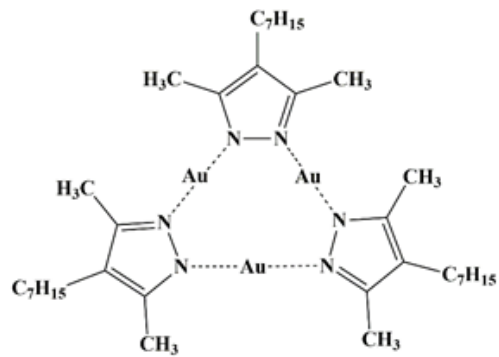

d)

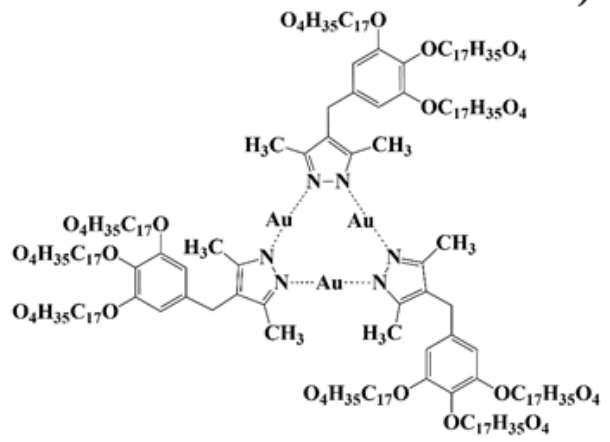

Figure 2. The structure of trinuclear gold complexes with a) two phenyl group with each substituted with two aliphatic (decyloxy) chains, b) heptyl substituent groups, c) octyl substituent groups and d) amphiphilic side chain [12-14]

In this work, $\left[\mathrm{Au}_{3} \mathrm{Pz}_{3}\right] \mathrm{C}_{10} \mathrm{TEG}$ was chosen as the subject matter as it was proven to exhibit room temperature liquid crystalline properties and its thin film metal nanocomposites have been successfully utilized in various applications including metal ion sensors [15], starting precursor for formation of gold nanoparticles [16,17], phosphorescence sensing and temperature imaging [18], as well as catalysis [19]. In addition, apart from using polarized optical microscope (POM), X-ray scattering experiment was mainly used as the technique to monitor the real-time structural changes of $\left[\mathrm{Au}_{3} \mathrm{Pz}_{3}\right] \mathrm{C}_{10} T E G$ as this method is very useful in investigating the LCs behaviour of compounds as being reported elsewhere [2022].

\section{Experimental}

\section{Synthesis and purification of $\left[\mathrm{Au}_{3} \mathrm{Pz}_{3}\right] \mathrm{C}_{10} \mathrm{TEG}$}

A solution of pyrazole ligand $\left(\mathrm{C}_{10} \mathrm{TEG}, 300.00 \mathrm{mg}, 0.26 \mathrm{mmol}\right)$ dissolved in dry tetrahydrofuran $(20.00$ $\mathrm{mL}$ ) was prepared in a Schlenk flask after being vacuum and flowed under $\mathrm{N}_{2}$ gas environment. Later, $\mathrm{Au}\left(\mathrm{SMe}_{2}\right) \mathrm{Cl}$ salt $(77.00 \mathrm{mg}, 0.26 \mathrm{mmol})$ was added into the flask and stirred for 10 minutes. Furthermore, a solution of potassium hydroxide $(\mathrm{KOH} ; 0.26 \mathrm{M}, 0.014 \mathrm{~g})$ in dry methanol $(1.00 \mathrm{~mL})$ was prepared and 
added dropwise to the flask using a Schlenk technique under continuous $\mathrm{N}_{2}$ flow. The reacting mixture was left to stir for overnight. After the completion of reaction, the mixture was filtered via in-situ filtration for any insoluble solids. The collected solution was transferred in a flask and evaporated to dryness in order to remove the solvent. The residue was firstly purified by using column gravity chromatography before being further purified by using recycling size exclusion chromatography to give $\left[\mathrm{Au}_{3} \mathrm{Pz}_{3}\right] \mathrm{C}_{10} \mathrm{TEG}$ as a pale-yellow sticky solid $(150.00 \mathrm{mg}, 0.03 \mathrm{mmol})$ as being reported in our previous work [17, 23].

\section{Results and discussion}

\section{Liquid crystalline properties $\left[\mathrm{Au}_{3} P \mathrm{z}_{3}\right] C_{10}$ TEG}

The successful synthesis and purification of $\left[\mathrm{Au}_{3} \mathrm{Pz}_{3}\right] \mathrm{C}_{10} \mathrm{TEG}$ has been discussed in detail in our previous works [17, 23], while its liquid crystalline property was firstly confirmed by using DSC as being reported elsewhere [14, 23]. Later, in-depth characterizations using variable-temperature POM and SAXS analysis were also carried out to further study the mesogenic behavior of $\left[\mathrm{Au}_{3} \mathrm{Pz}_{3}\right] \mathrm{C}_{10} \mathrm{TEG}$ as described in this work. Based on Lintang et al. [14], the DSC thermogram of $\left[\mathrm{Au}_{3} \mathrm{Pz}_{3}\right] \mathrm{C}_{10} \mathrm{TEG}$ clearly showed the room temperature liquid crystalline property. For the POM results, Figure 3a showed the POM image of $\left[A u 3 P z_{3}\right] C_{10} T E G$ before the heating started with no apparent textures of LCs, while Figure $3 b$ showed the image of $\left[\mathrm{Au}_{3} \mathrm{Pz}_{3}\right] \mathrm{C}_{10} \mathrm{TEG}$ after being melted until its isotropic state. Interestingly, Figure $3 \mathrm{c}$ and $3 \mathrm{~d}$ showed the formation of typical focal conic fan-shaped textures resembling the columnar discotic hexagonal liquid crystalline behavior of $\left[\mathrm{Au}_{3} \mathrm{Pz}_{3}\right] \mathrm{C}_{10} \mathrm{TEG}$ upon aging at $45^{\circ} \mathrm{C}$ for overnight.

a)

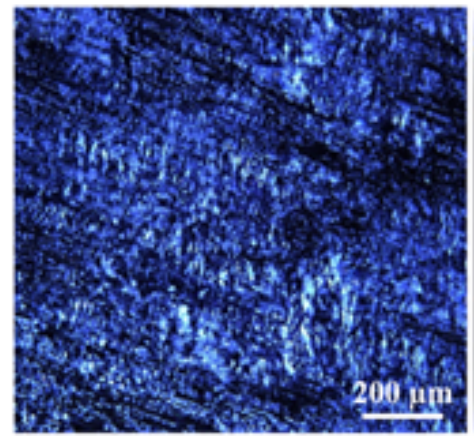

b)

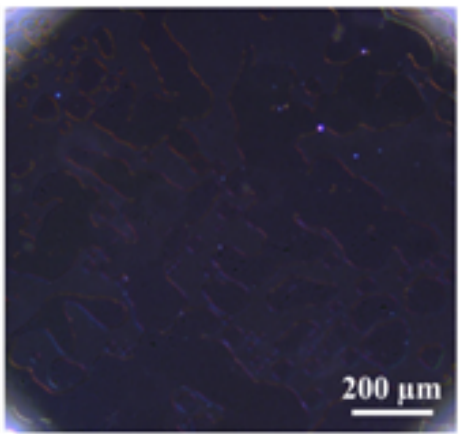

c)

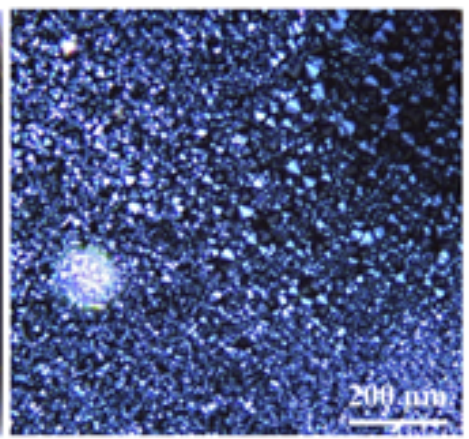

d)

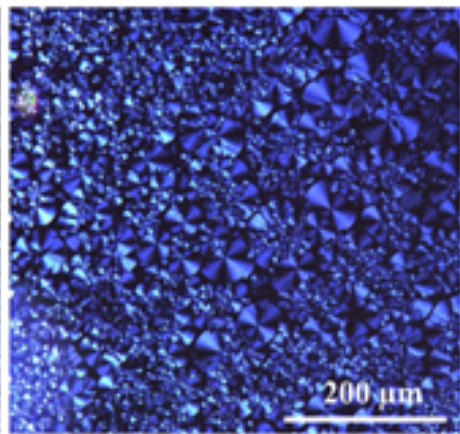

Figure 3: POM images of $\left[\mathrm{Au}_{3} \mathrm{Pz}_{3}\right] \mathrm{C}_{10} \mathrm{TEG}$ showing the images at a) room temperature before the heating started, b) its isotropic melt, c) the formation of fan-shaped textures after the sample was aged at $45{ }^{\circ} \mathrm{C}$ for overnight at $1{ }^{\circ} \mathrm{C}$ min-1 and d) 10 times magnification of image $\mathrm{c}$

Moreover, the SAXS analysis of $\left[\mathrm{Au}_{3} \mathrm{Pz}_{3}\right] \mathrm{C}_{10} \mathrm{TEG}$ showed prominent and well defined peaks in the range below $10^{\circ}$ as shown in Figure $4 a$ and $4 \mathrm{~b}$. Remarkably, the SAXS diffractogram displayed the presence of two types of discotic hexagonal pattern as summarized in Table 1. Generally, columnar hexagonal can give two types of arrangements which are ordered (Col $\mathrm{C}_{\text {ex/o }}$ ) or disordered (Col $\mathrm{hex}_{\mathrm{d}}$ ) with their respective defects as shown in Figure 4c. In this case, the peaks at $2.24^{\circ}$ (i), $4.12^{\circ}$ (iii), $4.46^{\circ}$ (iv) and $6.04^{\circ}$ (vii) represent the ordered hexagonal with corresponding d-spacing of 3.94, 2.14, 1.98 and 1.46 $\mathrm{nm}$, respectively, while peaks at $2.66^{\circ}$ (ii), $4.82^{\circ}(\mathrm{v}), 5.32^{\circ}$ (vi) and $6.68^{\circ}$ (viii) represent the disordered hexagonal with d-spacing of $3.32,1.83,1.66$ and $1.32 \mathrm{~nm}$, respectively. In addition, the 1D diffractogram in Figure 4a was in good agreement with the scattering rings of 2D views (Figure 4b). 
a)

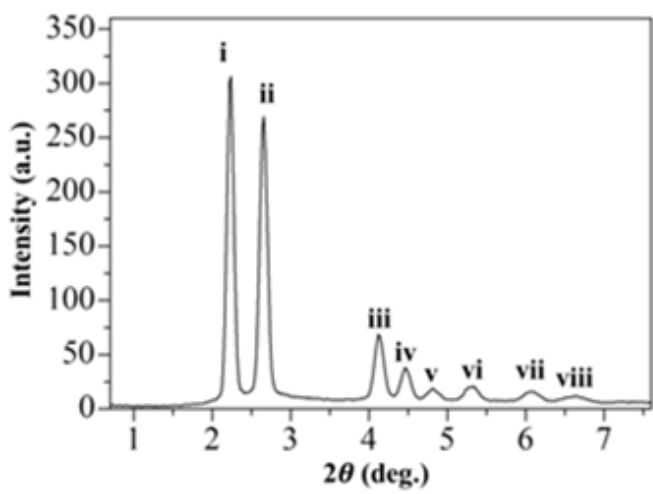

b)

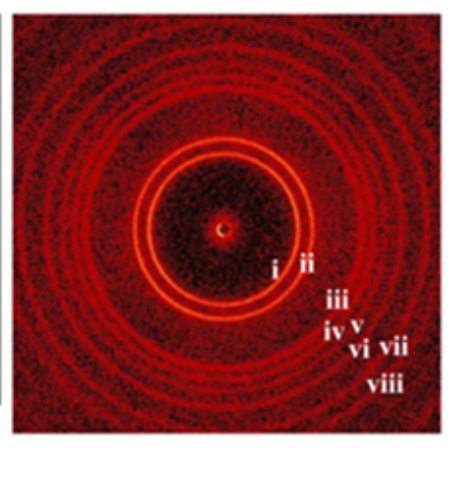

c)

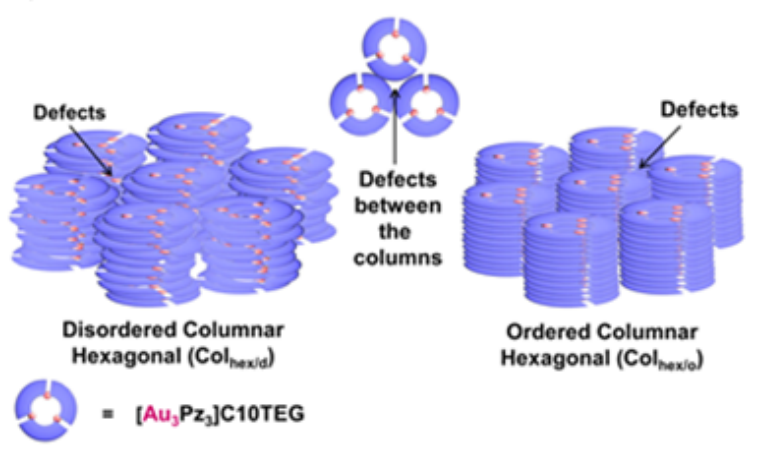

Figure 4. SAXS patterns of $\left[\mathrm{Au}_{3} \mathrm{Pz}_{3}\right] \mathrm{C}_{10} T E G$ in a) $1 \mathrm{D}$ and b) $2 \mathrm{D}$ views having both ordered and disordered hexagonal organization and $\mathrm{c}$ ) the illustrations of columnar ordered and disordered type of hexagonal arrangements

Table 1. Summary of SAXS pattern of $\left[\mathrm{Au}_{3} \mathrm{Pz}_{3}\right] \mathrm{C}_{10} \mathrm{TEG}$

\begin{tabular}{|c|c|c|}
\hline \multirow{2}{*}{$\begin{array}{l}\text { Miller Indices } \\
\quad(\mathbf{h}, \mathbf{k}, \mathrm{I})\end{array}$} & \multicolumn{2}{|c|}{ Position of Peaks $(2 \theta)$} \\
\hline & Hexagonal Disordered (deg.) & Hexagonal Ordered (deg.) \\
\hline $\mathrm{i}\left(d_{100}\right)$ & - & $2.24^{\circ}$ \\
\hline ii $\left(d_{100}\right)$ & 2.66 & - \\
\hline iii $\left(d_{110}\right)$ & - & $4.12^{\circ}$ \\
\hline iv $\left(d_{200}\right)$ & & $4.46^{\circ}$ \\
\hline $\mathrm{v}\left(d_{110}\right)$ & & - \\
\hline vi $\left(d_{200}\right)$ & - & - \\
\hline vii $\left(d_{210}\right)$ & $4.82^{\circ}$ & $6.04^{\circ}$ \\
\hline viii $\left(d_{210}\right)$ & $6.68^{\circ}$ & - \\
\hline
\end{tabular}

Furthermore, VT-SAXS analyses were carried out to study the phase transition and structural changes of $\left[\mathrm{Au}_{3} \mathrm{Pz}_{3}\right] \mathrm{C}_{10} \mathrm{TEG}$ upon heating and cooling cycle. VT-SAXS analyses in both $1 \mathrm{D}$ and $2 \mathrm{D}$ views as shown in Figure 5 to 8 further proved the thermotropic LC behavior of $\left[\mathrm{Au}_{3} P z_{3}\right] \mathrm{C}_{10} T E G$ with the mesophases range was in good agreement with DSC thermogram from Lintang et al. [14]. In the crystalline and liquid crystalline phase, all the peaks corresponding to the hexagonal arrangement (Col $\left.\right|_{\text {hex/o }}$ and $\mathrm{Col}_{\text {hex/d }}$ ) were observed clearly. When nanostructure $\left[\mathrm{Au}_{3} \mathrm{Pz}_{3}\right] \mathrm{C}_{10} \mathrm{TEG}$ was heated until reaching the isotropic phase at $40{ }^{\circ} \mathrm{C}$ in the first heating cycle, the $1 \mathrm{D}$ and $2 \mathrm{D}$ view of SAXS pattern started to diminish before disappeared completely at $45^{\circ} \mathrm{C}$ and above, indicating a complete isotropic arrangement was occurred (Figure 5 and 6). Subsequently, when $\left[\mathrm{Au}_{3} \mathrm{Pz}_{3}\right] \mathrm{C}_{10} \mathrm{TEG}$ was cooled down during the first cooling cycle, the SAXS pattern was successfully recovered and maintained its mesophase range until it was in fully crystalline phase at $5^{\circ} \mathrm{C}$ and below (Figure 7 and 8). Interestingly, $\left[\mathrm{Au}_{3} \mathrm{Pz} 3\right] \mathrm{C}_{10}$ TEG still maintained the same patterns upon being heated and cooled for the second cycle (Figure S1-S4). This clearly indicate that $\left[\mathrm{Au}_{3} \mathrm{Pz}_{3}\right] \mathrm{C}_{10} \mathrm{TEG}$ belongs to the thermotropic type as it showed 
a phase transition into LCs upon temperature changes. In addition, $\left[\mathrm{Au}_{3} \mathrm{Pz}_{3}\right] \mathrm{C}_{10} \mathrm{TEG}$ can also be categorized as enantiotropic LCs as it can exhibit mesogenic properties by both upon lowering the temperature of a liquid or increasing the temperature of a solid.
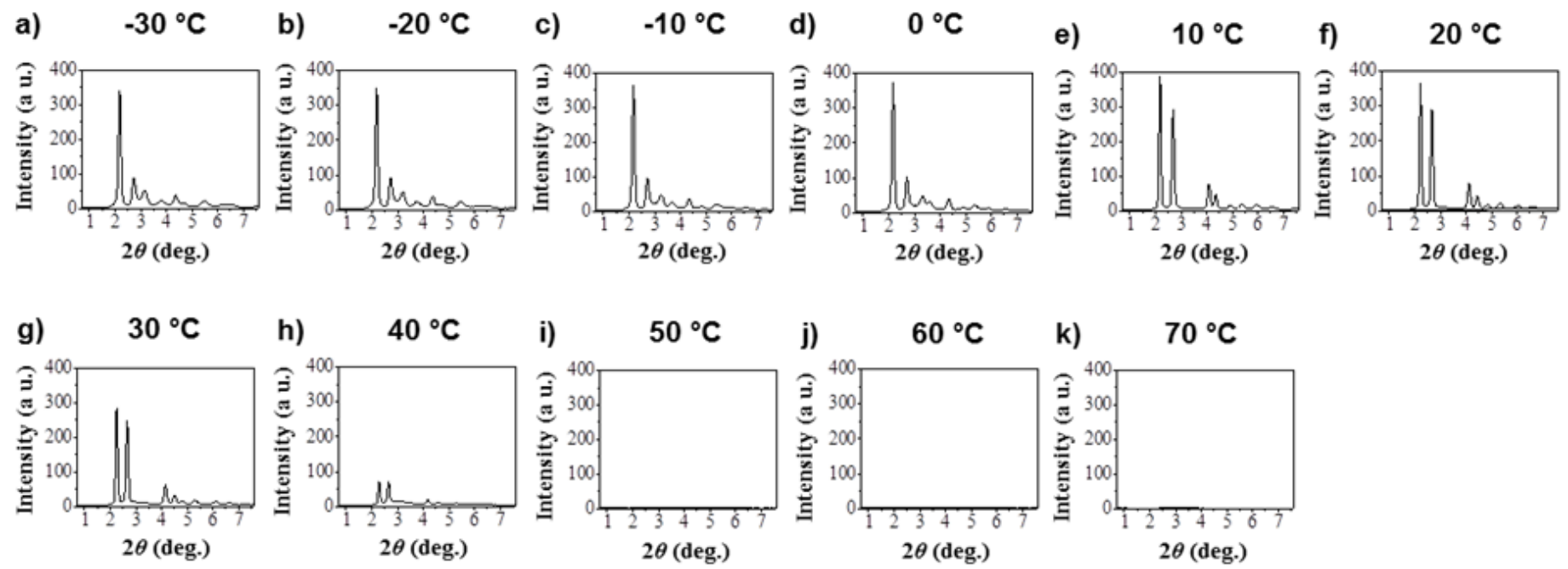

Figure 5. VT-SAXS patterns in $1 \mathrm{D}$ view of $\left[\mathrm{Au}_{3} \mathrm{Pz}_{3}\right] \mathrm{C}_{10} \mathrm{TEG}$ upon first heating cycle from -30 to $70{ }^{\circ} \mathrm{C}$ range at a) $\left.-30, \mathrm{~b}\right)-20$, c) -10 , d) 0, e) 10, f) 20, g) 30, h) 40 , i) 50, j) 60 , and k) $70^{\circ} \mathrm{C}$
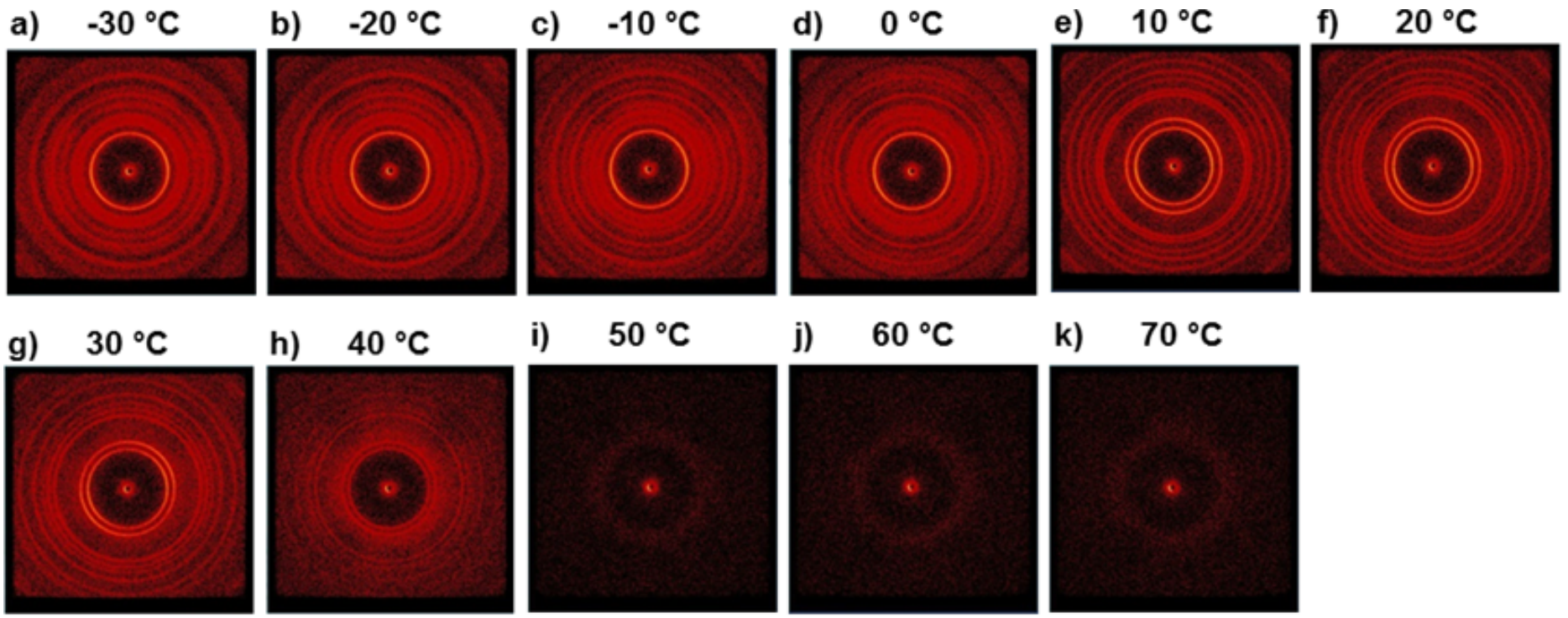

k) $\quad 70^{\circ} \mathrm{C}$

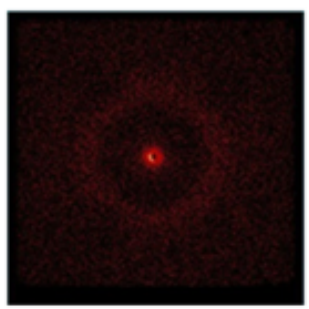

Figure 6. VT-SAXS patterns in $2 \mathrm{D}$ view of $\left[\mathrm{Au}_{3} \mathrm{Pz}_{3}\right] \mathrm{C}_{10}$ TEG upon first heating cycle from -30 to $70{ }^{\circ} \mathrm{C}$ at a) -30 , b) -20 , c) -10 , d) 0 , e) 10 , f) 20, g) 30, h) 40 , i) 50, j) 60 , and k) $70{ }^{\circ} \mathrm{C}$ 

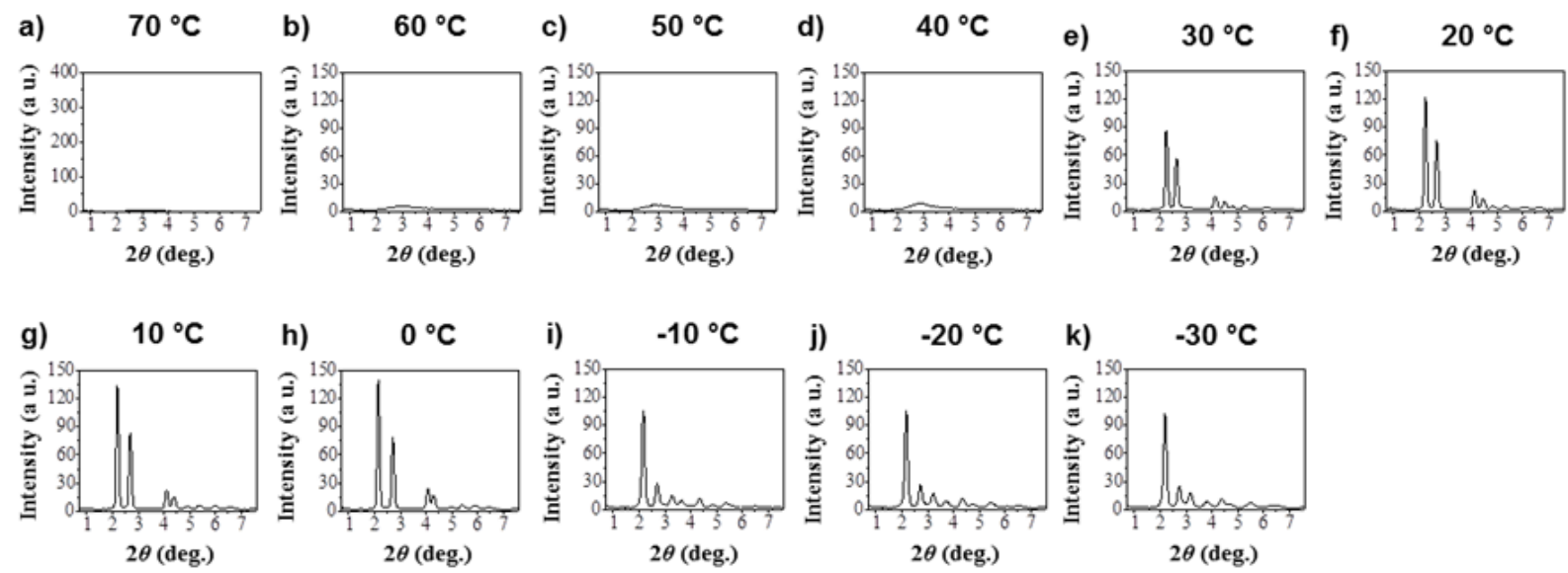

Figure 7. VT-SAXS patterns with $1 \mathrm{D}$ view of $\left[\mathrm{Au}_{3} \mathrm{Pz}_{3}\right] \mathrm{C}_{10} \mathrm{TEG}$ upon first cooling cycle from 70 to $-30{ }^{\circ} \mathrm{C}$ at a) 70 , b) 60 , c) 50 , d) 40 , e) 30, f) 20, g) 10, h) 0, i) -10, j) -20 , and k) $-30^{\circ} \mathrm{C}$
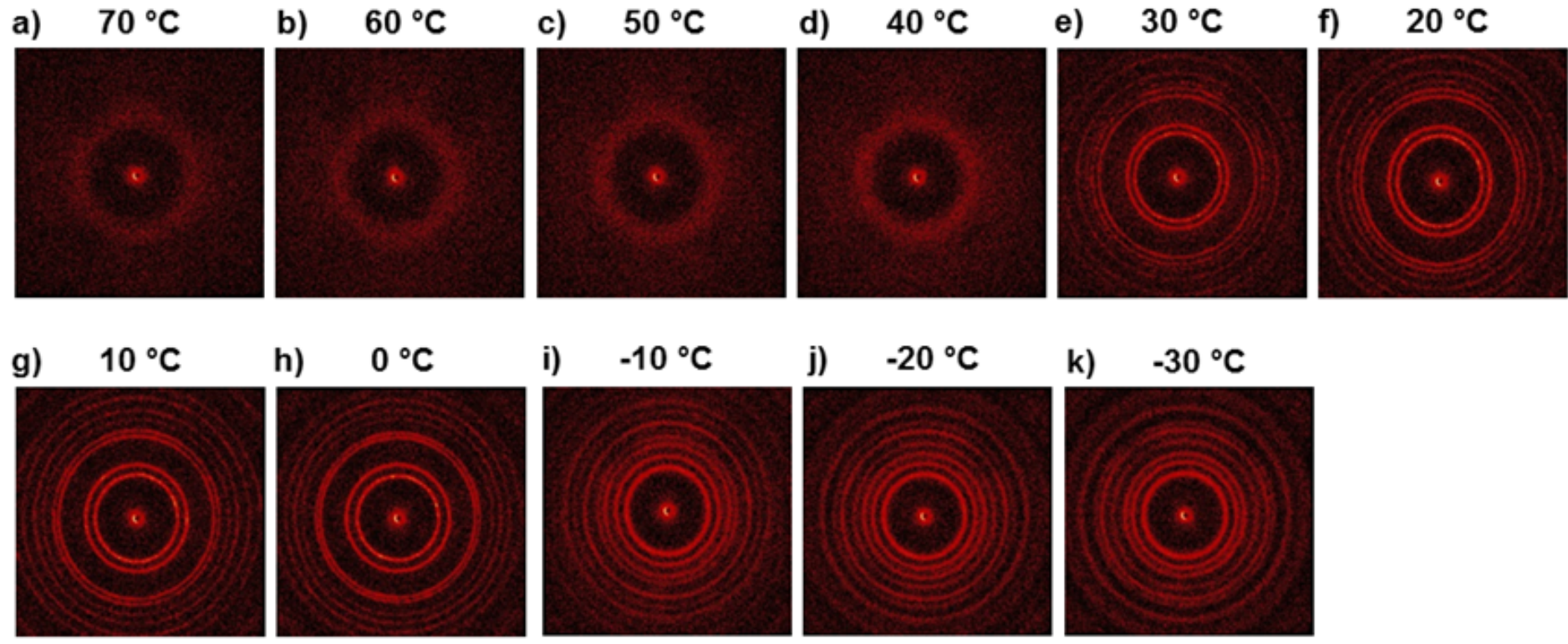

Figure 8. VT-SAXS patterns with $2 \mathrm{D}$ view of $\left[\mathrm{Au}_{3} \mathrm{Pz}_{3}\right] \mathrm{C}_{10} \mathrm{TEG}$ upon first cooling cycle from 70 to $-30{ }^{\circ} \mathrm{C} \mathrm{at} \mathrm{a)} 70$, b) 60 , c) 50 , d) 40 , e) 30, f) 20, g) 10, h) 0, i) -10, j) -20 , and k) $-30^{\circ} \mathrm{C}$

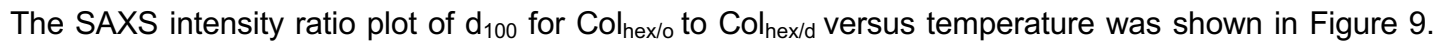
Interestingly, columnar nanostructure $\left[\mathrm{Au}_{3} \mathrm{Pz}_{3}\right] \mathrm{C}_{10} \mathrm{TEG}$ having a crystalline phase at lower temperature in the first heating-cooling cycle showed a large SAXS intensity ratio of $d_{100}$ for Col $\mathrm{hex}_{\text {ho }}$ to Col $\mathrm{l}_{\text {hex/d }}$ as illustrated in the figure. During crystalline phase, single molecule of $\left[\mathrm{Au}_{3} \mathrm{Pz}_{3}\right] \mathrm{C}_{10} \mathrm{TEG}$ tends to arrange themselves towards a more organized and ordered hexagonal arrangements so that it decreased the $\mathrm{d}_{100}$ intensity of disordered hexagonal. Hence, majority of hexagonal arrangements in the $\left[\mathrm{Au}_{3} \mathrm{Pz}_{3}\right] \mathrm{C}_{10} \mathrm{TEG}$ at lower temperature (crystalline phase) was the Col hex/o with percentage range between 79.1 to $78.4 \%$ during first heating period. On the other hand, the SAXS intensity ratio of $\mathrm{d}_{100}$ for Col hex/o to $\mathrm{Col}_{\text {hex/d }}$ started to decrease upon entering the mesophase range, suggesting an increasing formation of $\mathrm{Col}_{\text {hex/d }}$ up to $48.9 \%$. When the material was fully melted, both Col hex/o and Col hex/d peaks were not observed, indicating a complete disarray organization of the molecule while in its isotropic state. The 
estimation for percentage of $\mathrm{Col}_{\text {hex/o }}$ and $\mathrm{Col}$ hex/d arrangements of $\left[\mathrm{Au}_{3} \mathrm{Pz}_{3}\right] \mathrm{C}_{10} \mathrm{TEG}$ at certain temperature for first heating was summarized in Table 2.
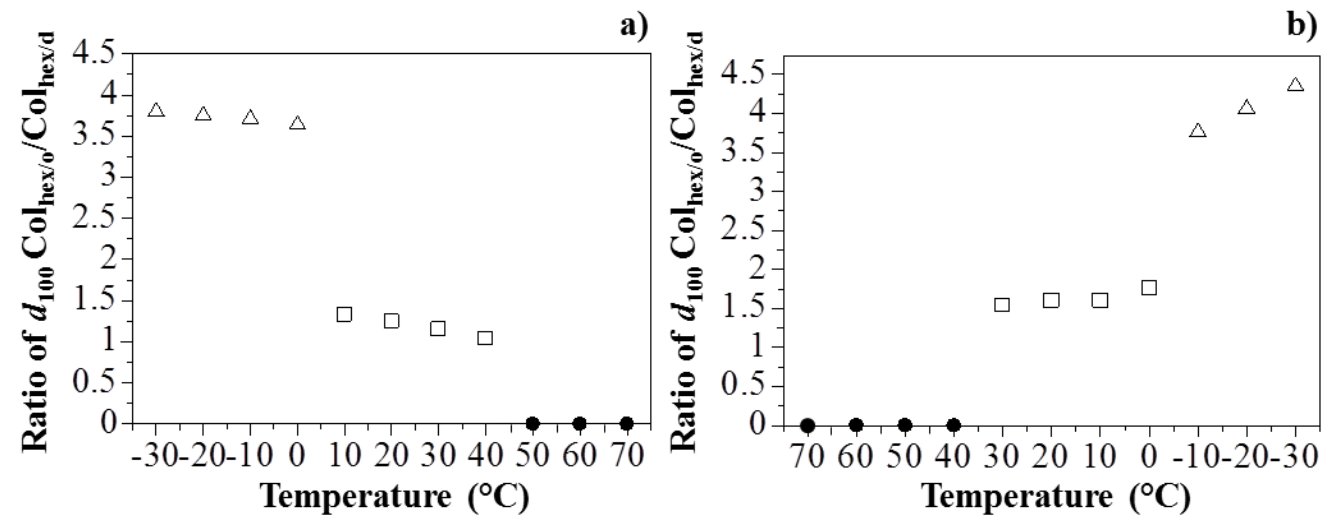

Figure 9. Plot of SAXS intensity ratio of $d_{100}$ for $\mathrm{Col}_{\text {hex/o }} / \mathrm{Col}_{\text {hex/d }}$ versus temperature upon first a) heating and b) cooling cycle exhibited by columnar nanostructure $\left[\mathrm{Au}_{3} \mathrm{Pz}_{3}\right] \mathrm{C}_{10} \mathrm{TEG}$ in its crystalline $(\Delta)$, mesophases $(\square)$ and isotropic $(\bullet)$ state

Table 2. Estimation for percentage of $\mathrm{Col}_{\text {hex/o }}$ and $\mathrm{Col}_{\text {hex/d }}$ in $\left[\mathrm{Au}_{3} \mathrm{Pz}_{3}\right] \mathrm{C}_{10} \mathrm{TEG}$ at certain temperatures based on SAXS intensity for first heating cycle

\begin{tabular}{|c|c|c|c|c|}
\hline Temperature $\left({ }^{\circ} \mathrm{C}\right)$ & $\begin{array}{c}\text { Intensity of } \\
d_{100} \text { Col }_{\text {hex/o }} \\
\text { (a. u. })\end{array}$ & $\begin{array}{c}\text { Intensity of } \\
d_{100} \mathrm{Col}_{\text {hex/d }} \\
\text { (a. u.) }\end{array}$ & $\begin{array}{c}\text { Percentage of } \\
\text { Col }_{\text {hex/o }}(\%)\end{array}$ & Percentage of $\mathrm{Col}_{\text {hex/d }}(\%)$ \\
\hline-30 & 341.7 & 89.8 & 79.1 & 20.9 \\
\hline-20 & 350.1 & 93.2 & 78.9 & 21.1 \\
\hline-10 & 360.0 & 97.0 & 78.7 & 21.3 \\
\hline 0 & 373.1 & 102.3 & 78.4 & 21.6 \\
\hline 10 & 389.7 & 291.6 & 57.1 & 42.9 \\
\hline 20 & 363.4 & 290.7 & 55.5 & 44.5 \\
\hline 30 & 286.4 & 247.6 & 53.6 & 46.4 \\
\hline 40 & 73.1 & 69.8 & 51.1 & 48.9 \\
\hline 50 & - & - & - & - \\
\hline 60 & - & - & - & - \\
\hline 70 & - & - & - & - \\
\hline
\end{tabular}

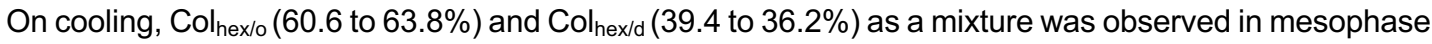
period, before the $\mathrm{Col}_{\text {hex/o }}$ arrangements started to increase until $79.0 \%$ at $-10{ }^{\circ} \mathrm{C}$. Further cooling treatment gave more $\mathrm{Col}_{\text {hex/o }}$ structure with percentage up to $81.3 \%$ at $-30{ }^{\circ} \mathrm{C}$. The SAXS peaks corresponding to $\mathrm{Col}_{\text {hex/d }}$ were also shifted to lower angle to approach the Col hex/o peaks upon temperature decrease. The estimation for percentage of Colnex/o and Colhex/d arrangements of $\left[\mathrm{Au}_{3} \mathrm{Pz}_{3}\right] \mathrm{C}_{10} \mathrm{TEG}$ at certain temperature for first cooling trend was summarized in Table 3 . Moreover, the variable-temperature SAXS analysis is in good agreement with the DSC results [23] showing a wide 
liquid crystalline property within room-temperature range $\left(-7.2\right.$ to $\left.43^{\circ} \mathrm{C}\right)$. In sharp contrast with our work, gold pyrazolate complexes typically displayed a narrow liquid crystalline property above the roomtemperature (more $25^{\circ} \mathrm{C}$ ) [12-13]. The possible reason on the dissimilar liquid crystals properties is contributed by the nature of the side chains of the gold complex structure.

Table 3. Estimation for percentage of Colnex/o and Colnex/d in $\left[\mathrm{Au}_{3} \mathrm{Pz}_{3}\right] \mathrm{C}_{10} \mathrm{TEG}$ at certain temperatures based on SAXS intensity for first cooling cycle

\begin{tabular}{|c|c|c|c|c|}
\hline Temperature $\left({ }^{\circ} \mathrm{C}\right)$ & $\begin{array}{c}\text { Intensity of } \\
d_{100} \text { Col hex/o } \\
\text { (a. u.) }\end{array}$ & $\begin{array}{c}\text { Intensity of } \\
d_{100} \text { Col hex/d } \\
\text { (a. u.) }\end{array}$ & $\begin{array}{l}\text { Percentage of } \\
\text { Col hex/o (\%) }\end{array}$ & Percentage of $\mathrm{Col}_{\text {hex/d }}(\%)$ \\
\hline 70 & - & - & - & - \\
\hline 60 & - & - & - & - \\
\hline 50 & - & - & - & - \\
\hline 40 & - & - & - & - \\
\hline 30 & 85.9 & 55.7 & 60.6 & 39.4 \\
\hline 20 & 121.9 & 75.9 & 61.6 & 38.4 \\
\hline 10 & 135.1 & 83.6 & 62.0 & 38.0 \\
\hline 0 & 139.9 & 79.3 & 63.8 & 36.2 \\
\hline-10 & 105.9 & 28.1 & 79.0 & 21.0 \\
\hline-20 & 106.4 & 26.2 & 80.2 & 19.8 \\
\hline-30 & 102.4 & 23.5 & 81.3 & 18.7 \\
\hline
\end{tabular}

\section{Conclusions}

This work focused on the in-depth study of columnar discotic hexagonal liquid crystaline behavior of $\left[\mathrm{Au}_{3} \mathrm{Pz}_{3}\right] \mathrm{C}_{10}$ TEG upon heating and cooling in real-time via VT-POM and VT-SAXS analysis. The results obtained have proven that $\left[\mathrm{Au}_{3} \mathrm{Pz}_{3}\right] \mathrm{C}_{10} \mathrm{TEG}$ showed mesogenic properties based on the focal conic fanshaped textures in POM images to support the previously reported DSC thermogram. Based on the SAXS pattern with their $1 \mathrm{D}$ and $2 \mathrm{D}$ view, it was found out that $\left[\mathrm{Au}_{3} \mathrm{Pz}_{3}\right] \mathrm{C}_{10} \mathrm{TEG}$ might consist of two types of stacking system, which are ordered or disordered hexagonal discotic arrangements. Moreover, it was also confirmed that $\left[\mathrm{Au}_{3} \mathrm{Pz}_{3}\right] \mathrm{C}_{10} T E G$ belongs to both thermotropic and enantiotropic $\mathrm{LCs}$, as it showed a phase transition into LCs upon temperature changes and can exhibit mesogenic properties upon lowering the temperature of a liquid or increasing the temperature of a solid.

\section{Acknowledgments}

The authors are grateful to Fundamental Research Grant Scheme (FGRS) from Ministry of Higher Education (MOHE) under vote FRGS/1/2020/STG05/USIM/03/2 for financial support. The authors also thank Centre for Sustainable Nanomaterials, Ibnu Sina Institute for Scientific and Industrial Research (ISI-SIR) and Unit Pengurusan Makmal Universiti (UPMU), Universiti Teknologi Malaysia (UTM), Malaysia as well as Universiti Sains Islam Malaysia (USIM) for characterization facilities.

\section{Supplementary Materials}

Figure S1. VT-SAXS patterns in 1D view of $\left[\mathrm{Au}_{3} \mathrm{Pz}_{3}\right] \mathrm{C}_{10} \mathrm{TEG}$ upon second heating cycle from -30 to 70 ${ }^{\circ} \mathrm{C}$ range at a) -30 , b) -20 , c) -10 , d) 0 , e) 10 , f) 20 , g) 30 , h) 40 , i) 50 , j) 60 , and k) $70{ }^{\circ} \mathrm{C}$. Figure S2. VT- 
SAXS patterns in $2 \mathrm{D}$ view of $\left[\mathrm{Au}_{3} \mathrm{Pz}_{3}\right] \mathrm{C}_{10}$ TEG upon second heating cycle from -30 to $70{ }^{\circ} \mathrm{C}$ at $\left.\mathrm{a}\right)-30$, b) -20 , c) -10 , d) 0 , e) 10, f) 20, g) 30 , h) 40 , i) 50 , j) 60 , and k) $70{ }^{\circ} \mathrm{C}$. Figure S3. VT-SAXS patterns with $1 \mathrm{D}$ view of $\left[\mathrm{Au}_{3} \mathrm{Pz}_{3}\right] \mathrm{C}_{10}$ TEG upon second cooling cycle from 70 to $-30{ }^{\circ} \mathrm{C}$ at a) 70 , b) 60 , c) 50 , d) 40 , e) 30, f) 20, g) 10, h) 0, i) -10, j) -20 , and k) $-30{ }^{\circ} \mathrm{C}$. Figure S4. VT-SAXS patterns with $2 \mathrm{D}$ view of $\left[\mathrm{Au}_{3} \mathrm{Pz}_{3}\right] \mathrm{C}_{10}$ TEG upon second cooling cycle from 70 to $-30^{\circ} \mathrm{C}$ at a) 70 , b) 60 , c) 50 , d) 40 , e) 30, f) 20 , g) 10 , h) 0, i) -10, j) -20 , and k) $-30{ }^{\circ} \mathrm{C}$.

\section{References}

[1] P. J. Collings and M. Hird, "Introduction to liquid crystals: Chemistry and Physics", CRC Press., 1997.

[2] F. Reinitzer, "Beiträge zur kenntniss des cholesterins". Monatshefte für Chemie/Chemical Monthly, 9(1), pp. 421-441,1888.

[3] H. K. Bisoyi and S. Kumar, "Liquid-crystal nanoscience: an emerging avenue of soft self-assembly", Chemical Society Reviews, 40(1), pp. 306-319, 2011.

[4] A. M. F. Neto and S. R. Salinas, "The physics of lyotropic liquid crystals: Phase transitions and structural properties", OUP Oxford, vol. 62, 2005.

[5] D. Demus, "One hundred years of liquid-crystal chemistry: Thermotropic liquid crystals with conventional and unconventional molecular structure", Liquid Crystals, 5(1), pp. 75-110, 1989.

[6] F. Guillén-González and G. Tierra, "Approximation of smectic-a liquid crystals", Computer Methods in Applied Mechanics and Engineering, 290, pp. 342-361, 2015.

[7] S. Kumar, "Self-organization of disc-like molecules: Chemical aspects", Chemical Society Reviews, 35(1), pp. 83-109, 2006.

[8] A. Okabe, T. Fukushima, K. Ariga et al., "Color-tunable transparent mesoporous silica films: immobilization of one-dimensional columnar charge-transfer assemblies in aligned silicate nanochannels", Angewandte Chemie International Edition, 41, pp. 3414-3417, 2002.

[9] X. Feng, V. Marcon, Pisula, W, et al., "Towards high charge-carrier mobilities by rational design of the shape and periphery of discotics". Nature Materials, 8(5), pp. 421-426, 2009.

[10] H.O. Lintang, M.A. Jalani, L. Yuliati, et al., "Fabrication of mesoporous silica/alumina hybrid membrane film nanocomposites using template sol-gel synthesis of amphiphilic triphenylene", IOP Conference Series: Materials Science and Engineering, vol. 202, No. 1, pp. 012003. IOP Publishing Ltd, 2017.

[11] J. Matmin, H. Osman, Q. Omar et al., "Photochemical synthesis of nanosheet tin di/sulfide with sunlight response on water pollutant degradation". Nanomaterials, 9(2), pp. 264, 2019.

[12] J. Barberá, A. Elduque, R. Giménez et al., "Pyrazolato gold complexes showing room-temperature columnar mesophases: Synthesis, properties, and structural characterization", Inorganic Chemistry, 37(12), pp. 29602967, 1998.

[13] S. J. Kim, S. H. Kang, K. M. Park et al., "Trinuclear gold(I) pyrazolate complexes exhibiting hexagonal columnar mesophases with only three side chains", Chemistry of Materials, 10(7), pp. 1889-1893, 1998.

[14] H. O. Lintang, K. Kinbara, K. Tanaka et al., "Self-Repair of a One-dimensional molecular assembly in mesoporous silica by a nanoscopic template effect", Angewandte Chemie International Edition, 49(25), pp. 4241-4245, 2010.

[15] H. O. Lintang, K. Kinbara, K. Tanaka et al., "Metal-ion permeation in congested nanochannels: the exposure effect of ag+ ions on the phosphorescent properties of a gold(I)-pyrazolate complex that is confined in the nanoscopic channels of mesoporous silica", Chemistry-An Asian Journal, 7(9), 2012.

[16] M. A. Jalani, L. Yuliati, S. Endud et al., "Synthesis of mesoporous silica nanocomposites for preparation of gold nanoparticles". Advanced Materials Research, 925, pp. 233-237, 2014a.

[17] M. A. Jalani, L. Yuliati, and H. O. Lintang, "Thermal hydrogen reduction for synthesis of gold nanoparticles in the nanochannels of mesoporous silica composite". Jurnal Teknologi, 70, pp. 131-136, 2014.

[18] H. O. Lintang, L. Yuliati, and S. Endud, "Phosphorescent sensing and imaging of temperature using mesoporous silica/gold nanocomposites", Materials Research Innovations, 18, pp. 444-448, 2014.

[19] M. A. Jalani, L. Yuliati, S. L. Lee et al., "Highly ordered mesoporous silica film nanocomposites containing gold nanoparticles for the catalytic reduction of 4-nitrophenol”. Beilstein journal of nanotechnology, 10(1), pp. 13681379, 2019.

[20] R. J. Mandle, S. J. Cowling and J. W. Goodby, "Combined microscopy, calorimetry and x-ray scattering study of fluorinated dimesogens". Scientific Reports, 7(1), pp. 13323, 2017.

[21] F. Camerel, F. Barrière and O. Jeannin, "Simulation of SAXS patterns of hexa-n-alkoxy-2, 3, 6, 7, 10, 11triphenylene mesophase". Liquid Crystals, 45(5), pp. 698-702, 2018.

[22] P. K. Bhowmik, S. T. Killarney, J. R. A. Li et al., "Thermotropic liquid-crystalline properties of extended viologen bis (triflimide) salts”. Liquid Crystals, 45(6), pp. 872-885, 2018.

[23] M. A. Jalani, L. Yuliati, S. L. Lee et al., "Size-exclusion liquid chromatography for effective purification of amphiphilic trinuclear gold(I) pyrazolate complex", Malaysian Journal of Fundamental and Applied Sciences, 14(1-2), pp. 133-137, 2018. 